\title{
INDIVIDUALIDADE E LIMINARIDADE: CONSIDERAÇÕES SOBRE OS RITOS DE PASSAGEM E A MODERNIDADE*
}

Roberto DaMatta

Deixe-me começar com uma história contada por Karl Popper que acredito - revela muito das minhas relações com o Museu Nacional, com o seu Programa de Pós-Graduação em Antropologia Social, com o seu atual coordenador, meu querido amigo Otávio Velho, com muitos de vocês, com os novos alunos neste momento de abertura de um novo ano letivo e, em especial, com o professor Luís de Castro Faria, cujo nome é hoje honrado nesta conferência que tenho a satisfação de pronunciar. Diz Popper que um divulgador científico, tendo que falar em um presídio, começou sua preleção com as seguintes palavras: “Hoje vou apresentar aqui a mesma conferência que fiz há seis anos. Por conseguinte, se alguém já a tiver ouvido é porque bem o merece!".

Que minhas palavras iniciais sejam, portanto, para falar de minha felicidade por ter recebido esse convite que homenageia, pela forma nobre de uma aula, um colega mais velho que foi meu primeiro professor de antropologia.

Ao lembrar a prisão e o fato tão simbolicamente real de que todos aqui presentes são prisioneiros desse Museu e desses ideais de saber, de pesquisar e de compreender os nossos semelhantes através da antropologia social ou cultural, quis me referir àquele destino comum e àquela solidariedade compartilhada pelos presidiários. No nosso caso, a cumplicidade de remar contra a corrente do poder e do dinheiro, o acordo tácito que faz com que todos se sintam, apesar das diferenças e até mesmo de eventuais antipatias, parte de um mesmo ideal. Pois na vida acadêmica, como nos grandes amores, somos todos aprisionados pelas formas mais densas de reciprocidade, aquelas que nos obrigam a reconhecer e a louvar, de tempos em tempos, as nossas dívidas e dúvidas para pessoas, idéias e métodos.

É, pois, importante reconhecer esse meu aprisionamento ao Museu Nacional e a esse grupo de antropólogos que, permitam-me a falsa modés- 
tia, ajudei a formar e a constituir, e que durante anos tem sido o sustentáculo de um diálogo intelectual importante para mim. A prova disso é que vocês irão ouvir um alinhavado de pensamentos que tenho externado ao longo desses últimos vinte anos, pois duas décadas se passaram desde que tratei deles, embrionariamente, é verdade, no meu livro Carnavais, Malandros e Heróis, e em dois ensaios publicados, ambos, em 1979.

Nesta conferência, falarei sobre um elo, que me parece crítico, entre dois conceitos fundamentais (e formidáveis) das ciências sociais. Discorrerei sobre a idéia de liminaridade (ou de soleira), um conceito engendrado pela tradição antropológica dos estudos detalhados, em geral romanticamente autocontidos e referidos ${ }^{1}$; e sobre a idéia de individualidade, que é uma noção central da tradição clássica dos estudos sociohistóricos das grandes civilizações, bem como uma categoria crucial e familiar do nosso universo cívico e político.

A noção de liminaridade leva-nos ao reino dos ritos de passagem e aos costumes exóticos dos grupos tribais; a idéia de individualidade, ao domínio da filosofia política, ao universo do mercado e do capitalismo, enfim, ao nosso próprio cotidiano, ao nosso universalismo implícito e inconsciente - aos nossos hábitos do coração. O primeiro termo liga-se ao nome de Arnold Van Gennep e, naturalmente, à obra de Victor Turner que - ao lado de Mary Douglas, Max Gluckman e Edmund Leach — é o principal responsável por seu resgate, caracterização e popularização nos estudos antropológicos modernos. O segundo termo remete à obra de Maine, Morgan, Sabine, Tocqueville (que, como se sabe, inventou, em 1842, a expressão individualismo) e, naturalmente, às idéias críticas de Max Weber e de Louis Dumont. Isso para não mencionar os pais fundadores do pensamento crítico e dos valores modernos: Maquiavel, Adam Smith, Hobbes, Locke e Rousseau.

É minha intenção, nesta palestra, indicar como uma passagem pode ser descoberta entre essas duas áreas conceituais aparentemente tão distantes, quando focalizamos certos aspectos ainda não discutidos dos ritos de passagem. 
Quero iniciar com uma breve caracterização da noção de individualidade, explicitando o modo pelo qual leio seus elos ideológicos e conceituais e a tradição de estudos da qual esta categoria faz parte. Será apenas óbvio reafirmar que individualidade se associa fortemente à tradição clássica da filosofia política, uma tradição que moldou o pensamento social moderno. Um modo de pensar a sociedade historicamente fundado e, em conseqüência, sumamente preocupado com as conexões entre instituições, práticas sociais e esferas percebidas como críticas (e universais) como o "religioso", o "político" e o "econômico. Nessa tradição, não se deixou de lado a discussão entre valores religiosos e as predisposições políticas e econômicas, e como essas esferas se influenciavam mutuamente. A obra de Weber é o melhor exemplo dessa abordagem.

A questão central aqui, como Dumont tornou claro e repetidamente acentuou, indo além do ensaio clássico de Marcel Mauss (1974) sobre a idéia do "eu", é a diferenciação crítica entre o indivíduo como realidade empírica e o estabelecimento deste como uma entidade social autônoma ou um valor social - um fenômeno sociopolítico importantíssimo, original e primordialmente associado à ideologia construída na Europa Ocidental, agigantada nos Estados Unidos e contemporaneamente massificada por meio de um processo mundial de aculturação. A pergunta básica para a pesquisa dentro dessa tradição tem sido: como podemos caracterizar o desenvolvimento da Europa Ocidental em relação ao de outras áreas do mundo? $\mathrm{Ou}$, mais concretamente, como entender a presença do capitalismo, da igualdade política e de suas éticas concomitantes, a "liberação" do indivíduo daquilo que é percebido como um conjunto de velhas repressões, tabus ou constrangimentos morais, somente no "Ocidente"? E, por contraste, a sua relativa ausência das chamadas "grandes civilizações" como as que surgiram no Oriente Médio, na Ásia e, permitam que eu mencione, porque é disso que tenho tratado no meu trabalho, nas sociedades tribais e no Brasil?

Meu ponto de vista é que esse problema diz respeito a uma passagem da individualização (e da individualidade), que — permitam-me a grande narrativa - são experiências da condição humana, para o individualismo, que é uma ideologia (um valor ou uma determinação social coercitiva e consciente) central apenas na chamada civilização ocidental. Assim, se a individualização é uma experiência universal, destinada a ser culturalmente reconhecida, marcada, enfrentada ou levada em consideração por todas as sociedades humanas, o individualismo é uma sofis- 
ticada elaboração ideológica particular ao Ocidente, mas que, não obstante, é projetada em outras sociedades e culturas como um dado universal da experiência humana.

É precisamente esse deslocamento sociológico, em suas múltiplas oscilações, combinações e variações que caracteriza o mundo moderno. De fato, a modernidade não fala apenas daquilo que é novo ou atual (como pensam alguns jornalistas e muitos cientistas políticos), mas diz respeito à institucionalização do indivíduo como valor englobante, um valor postulado como sendo maior (e mais inclusivo) do que a sociedade da qual ele é parte.

Se muitas das sociedades e culturas do mundo reconhecem e são capazes de institucionalizar a experiência da individualidade (a experiência fundamental de estar fora-do-mundo e, portanto, livre de obrigações sociais imperativas e rotineiras) nos papéis históricos do profeta, do líder messiânico, do mistagogo, do místico, do curador, do xamã, do feiticeiro, do bandido social, dos santos, dos caudilhos, dos peregrinos, dos mártires e, em parte, dos malandros, foi somente na civilização ocidental que a experiência do indivíduo isolado do grupo passou a ser uma instituição central e normativa. Entre nós, portanto, o indivíduo não é somente uma parte essencial do mundo, mas é também um ser dotado de uma independência e de uma autonomia que não tem paralelo em nenhuma outra sociedade ${ }^{2}$.

A essa altura, vale a pena salientar que se essa problemática é marcante nas obras dos sociólogos clássicos, ela está, mesmo hoje em dia, conspicuamente ausente do trabalho dos antropólogos sociais.

\section{III}

A idéia de liminaridade liga-se ao livro de Arnold Van Gennep, Les Rites de Passage, publicado em 1909. Haveria muito o que falar sobre essa obra magistral, repleta de idéias novas e marcada por uma enorme erudição, na qual, pela primeira vez, os ritos são analisados sociologicamente, sendo tomados como expressões da dinâmica social. Nele, Van Gennep rompe pioneiramente com a universalidade da fisiologia como característica dos chamados "ritos de puberdade", resgata os ritos de passagem do seu plano de estudo individual e descobre, um tanto surpreso, que "dentro de uma multiplicidade de formas conscientemente expressas ou meramente implícitas, há um padrão típico sempre recorrente: o padrão dos ritos de passagem" (cf. Van Gennep 1978:191). Um padrão que implica- 
va três fases nitidamente distintas: separação, incorporação e, entre estas, uma fase liminar, fronteiriça, marginal, paradoxal e ambígua — um limem ou soleira - que, embora se produzisse em todas as outras fases, era destacada, focalizada e valorizada.

Os ritos de passagem foram recorrentemente interpretados a partir dos anos 60, sobretudo por Victor Turner. Pode-se discernir duas tendências interpretativas típicas dessa fase. A primeira, discute os ritos de passagem como uma resposta adaptativa obrigatória, quando os indivíduos são obrigados a mudar de posição dentro de um sistema. Deste ângulo, os ritos seriam elaborações sociais secundárias, com a função de aparar os conflitos gerados pela transição da adolescência à maturidade, uma passagem postulada inevitável, difícil, problemática e conflituosa em qualquer sociedade humana. Nessa perspectiva, o foco é sempre nos jovens e naquilo que é percebido como uma arriscada e conflituosa transição dentro da sociedade.

Típica dessa postura é, por exemplo, a interpretação da fase de reclusão nos ritos de passagem da sociedade Yawalapiti do Xingu, realizada por Thomas Gregor, na qual, como aponta criticamente Eduardo Viveiros de Castro (1987:36-37), se fala de um momento em que os imperativos sociais são relaxados e há, conseqüentemente, um saudável e bem-vindo retorno à velha privacidade, naquilo que seria o grato contato do indivíduo consigo mesmo. Uma privacidade, aliás, que surge claramente nas anedotas e relatos de campo dos antropólogos ingleses e americanos que insistem em ressaltar como os nativos deixavam pouco espaço para o gozo de sua "privacidade" (um amálgama de isolamento voluntário e individualidade). Como se o drama fundamental do trabalho de campo como um rito de passagem fosse justamente essa suspensão forçada da vida individual e a participação intensa e compulsória em um modo de existência coletivo ${ }^{3}$. Não é preciso acentuar que tal reação trai o peso do individualismo como um "hábito do coração", tal como essa ideologia se traduz e manifesta na cultura americana, um sistema em que o período dos 13 aos 19 anos — os anos teens, o momento das "iniciações" à vida adulta - é sublinhado como uma fase de exacerbação da subjetividade.

Nesse contexto, vale lembrar que o impacto do livro de Margaret Mead, Coming Age in Samoa (publicado em 1928 nos Estados Unidos), se deve justamente à demonstração de que em Samoa não havia conflitos na passagem da meninice para a vida adulta. Não havia uma "teenage culture" em Samoa, o que, por contraste, levava os americanos a descobrir em casa o conceito boasiano de cultura, bem como as idéias concomitantes de arbitrariedade simbólica e de relativismo cultural. 
A segunda tendência interpretativa revela uma mudança de foco do plano individual para o coletivo. A par de uma impressionante e detalhada etnografia, sua novidade consiste, precisamente, em tomar o simbolismo dos ritos de passagem como uma dramatização de valores, axiomas, conflitos e contradições sociais. Trata-se de mostrar que o ponto de vista deslocado, salientado na liminaridade, não configurava situações, processos ou papéis meramente pecaminosos, patológicos e criminosos, mas que era inerente à própria sociedade humana. Como sempre, a descoberta da positividade dos estados liminares e a discussão de sua importância como elemento essencial da constituição da própria sociabilidade, colocavam em crise os modos tradicionais de se discutir a marginalidade como um estado potencialmente criminoso, bem como o desvio como prépatologia ou perversão. Ademais, elas abriam a possibilidade de enfatizar a "licença ritual", esses momentos especiais opostos às prescrições político-legais, nos quais a sociedade se permitia ler-se a si própria de ponta-cabeça. Algo, sem dúvida, difícil de discutir em um sistema que institucionalizou a mediocridade e desenvolveu uma verdadeira alergia em relação a tudo que escapava de suas agendas e rotinas explícitas, como é o caso dos Estados Unidos.

\section{IV}

Descobri a possibilidade de relacionar liminaridade e individualidade quando me dediquei ao estudo do Brasil não só como nação (como os economistas, historiadores e cientistas políticos sempre fazem) mas também como um sistema social, ou sociedade (o que é uma outra coisa). No meu caso, mais especificamente, tratava-se de discutir práticas e valores sociais que coexistem e, às vezes, se opõem à nação, engendrando coletividades características, marcadas pela dissonância, pelo hibridismo e pelo diálogo nem sempre cordial entre o seu código nacional (cívico, burguês e capitalista - a sua "realidade oficial") e o seu quadro de valores lido como nãomoderno e, até mesmo - como é o caso de muitos Estados nacionais "antimoderno" (tanto que seus valores cotidianos têm sido associados, com inspiração em Alberto Torres, a um "Brasil real" - um Brasil mais "concreto" do que aquele formalmente desenhado pelas leis e pelas instituições oficiais que seria um "Brasil legal", porém ideal e falsificado) ${ }^{4}$.

Foi, pois, sob a luz dessa distinção que comecei a realizar uma crítica da literatura antropológica padrão sobre o conceito de liminaridade. Minha questão apresenta-se em dois blocos críticos. 
O primeiro nasce de uma releitura crítica das interpretações da liminaridade apresentadas nos ensaios seminais de Victor Turner, Mary Douglas, Edmund Leach, para ficar com a trindade dos estudos simbólicos. O que mais chama a minha atenção na obra desses mestres é a sua leitura da liminaridade como algo invariavelmente paradoxal, ambíguo e, no limite, perigoso e negativo; isto é, como um estado ou processo que desafia um sistema de classificação legalisticamente concebido como fixo, indiscutível e construído por categorias isoladas. Enfim, algo que - tal como ocorre com a concepção de sociedade puritana e com os esquemas burgueses dos quais esses autores são parte — não admite o mais-oumenos, a indecisão, o adiamento e, acima de tudo, o hibridismo, ou seja, a ausência de compartimentalização e de indivisibilidade. Para esses antropólogos, o ambíguo é todo objeto, ser ou instituição situado simultaneamente em dois campos semânticos mutuamente excludentes. É tudo aquilo que tem propriedades multivocais e contraditórias como o pangolim de Mary Douglas (1966), o animal doméstico de Leach (1964) e os neófitos de Turner (1964): aqueles noviços que contradizem o dilema hamletiano e "são e não são ao mesmo tempo". Como este último exprimiu em um ensaio memorável, repetindo o poeta vitoriano Robert Browning ${ }^{5}$, os iniciandos são esses seres que estão "betwixt and between".

Meu estranhamento com esse modo de tratar a liminaridade ocorreu quando, usando os instrumentos fornecidos por essa antropologia, estudei o Carnaval brasileiro para ali descobrir o lado positivo da liminaridade. Algo que, aliás, acentuei no meu livro, Universo do Carnaval: Imagens e Reflexões (1981), quando notei a alegria obrigatória dos estados carnavalescos caracterizada justamente por se estar betwixt and between, um momento especial demarcado por uma festa que, simultaneamente, salientava o coletivo e o individual, um ritual situado dentro e fora do mundo. E não, como queria Victor Turner (1974), em alguma manifestação de uma "antiestrutura" ou de algum sentimento destinado a negar a sociedade lida, conforme ele a concebia, como um conjunto de posições fixas - dentro daquele "legalismo" antropológico que tanto caracterizou a antropologia social de Radcliffe-Brown, de Meyer Fortes e de Max Gluckman - ou como uma casa, à Van Gennep.

O Carnaval é uma festa que, entre outras coisas, estimula a disputa, mas domestica, aristocratiza e hierarquiza a competitividade, fazendo com que ganhadores e perdedores se liguem entre si como grupos e entidades especiais. Festa, ademais, na qual se adotam tecnologias burguesas de criação identitária, mas se produz um sistema ideológico antiburguês e antipuritano, como a glorificação do feminino, do hedonismo, da 
sensualidade, do erotismo aberto e público, do sexo sem reprodução (na exaltação da analidade e do homossexualismo). Festa, enfim, que abre, em uma sociedade obcecada em tomar o chamado trem da modernidade e do capitalismo, uma brecha que rejeita agendas e controles, pois o Carnaval, como revelou Mikhail Bakhtin (1989), constrói-se pela suspensão temporária do senso burguês, sendo afim da loucura, do descontrole, do exagero, da caricatura, do grotesco, do desequilíbrio e da gastança. Festa, finalmente, que faculta "entrar" em um bloco, escola ou cordão para relativizar velhas e rotineiras relações e viver novas identidades que possibilitam leituras inovadoras do mundo. O que permite adquirir - tal como acontece com os sábios, anacoretas, xamãs, feiticeiros e renunciadores tradicionais - um conhecimento novo e diferenciado da sociedade e de si próprio.

Como, então, tomar o limem e o paradoxal como negativos em sistemas relacionais, como o Brasil, uma sociedade feita de espaços múltiplos, na qual uma verdadeira institucionalização do intermediário como um modo fundamental e ainda incompreendido de sociabilidade é um fato social corriqueiro? Como ter horror ao intermediário e ao misturado, se pontos críticos de nossa sociabilidade são constituídos por tipos liminares como o mulato, o cafuzo e o mameluco (no nosso sistema de classificação racial); o despachante (no sistema burocrático); a(o) amante (no sistema amoroso); o(a) santo(a), o orixá, o "espírito" e o purgatório (no sistema religioso); a reza, o pedido, a cantada, a música popular, a serenata (no sistema de mediação que permeia o cotidiano); a varanda, o quintal, a praça, o adro e a praia (no sistema espacial); o "jeitinho", o "sabe com quem está falando?" e o "pistolão" (nos modos de lidar com o conflito engendrado pelo encontro de leis impessoais com o prestígio e o poder pessoal); a feijoada, a peixada e o cozido, comidas rigorosamente intermediárias (entre o sólido e o líquido) no sistema culinário; a bolina e a "sacanagem" (no sistema sexual). Isso para não falar das celebridades inter, trans, homo ou pansexuais, que, entre nós, não são objeto de horror ou abominação (como ocorre nos Estados Unidos), mas de desejo, curiosidade, fascinação e admiração. Tudo isto me levou a repensar o ambíguo como um estado axiomaticamente negativo.

O segundo bloco crítico relaciona-se ao modo pelo qual a liminaridade é caracterizada, sobretudo na obra de Victor Turner, o estudioso que mais se preocupou com esse fenômeno, fazendo dele um instrumento de entendimento de muitas situações sociais por meio do conceito de communitas e de variantes como "liminóide". Por que, deve-se inicialmente questionar, o "liminar" é fruto de tanto mistério, ambigüidade e perigo 
nas sociedades tribais? Por que a fase de transição é a mais intrigante e a que apresenta um simbolismo mais rico nos ritos de passagem?

Para Turner, Leach e Douglas, a liminaridade é especial porque engendra uma ambigüidade classificatória. Ampliando essa idéia, Turner, no seu ensaio clássico publicado em 1964, adiciona outras dimensões sociais e simbólicas que salientam uma inelidível visão tipológica e relativamente estática do assunto.

Sendo assim, os estados liminares caracterizam-se pelos seguintes fatores:

1) pela evasão da estrutura jurídico-política cotidiana, das classificações cognitivas fundadas na lógica do isso ou aquilo, uma coisa ou outra - no princípio aristotélico do terceiro excluído (Douglas, Turner, Leach);

2) pela associação com a morte para o mundo (entre os Ndembu, o lugar da circuncisão é chamado de "lugar onde se morre") (Turner); 3) pela impureza, pois os noviços transgridem (e transcendem) as fronteiras classificatórias (Douglas, Turner);

4) pela identificação com objetos e processos anti-sociais (fezes) ou "naturais" (lactação, parto, desmame e gestação), com a conseqüente associação dos noviços aos embriões e crianças de peito (Turner);

5) pelo uso de línguas secretas, estranhas e/ou especiais (Van Gennep, Turner);

6) pela invisibilidade social plena, com a perda de nomes, insígnias, roupas (Turner);

7) pela associação com seres bi ou transexuais, como os andróginos, ou com animais que estão na interseção de duas classes e sinalizam estados negativos ou abomináveis (Turner, Leach, Douglas); e, finalmente,

8) pelos ordálios como a circuncisão, a subincisão, a supressão do clitóris, a exposição prolongada ao frio ou testes físicos impossíveis nos quais o fracasso é ridicularizado, bem como pela resposta a enigmas, adivinhações e resistência à punição física (Turner).

Para Turner e para os outros mestres dessa verdadeira "antropologia da ambigüidade"6, a lista sugere, entre outras coisas, um estado de "regressão" coletiva no qual os indivíduos perdem sua consciência de compartimentalização, autonomia e interioridade, para se transformarem em matéria-prima a ser moldada de acordo com certos valores sociais. Para ele, esse processo, que no livro O Processo Ritual (1974) desemboca no conceito de communitas, é, essencialmente, uma forte e singular (para não dizer, anômala) coletivização, marcada pelo contato com o que ele, usan- 
do uma expressão de Martin Buber, chama de "nós essencial", uma das dimensões mais importantes na constituição de um estado "antiestrutural", um estado destituído de individualidade e compartimentalização.

Lendo a liminaridade de modo substantivista, Turner não se dá conta de que esse processo pode variar de sistema para sistema, assumindo distintas conotações e adquirindo sentidos diferentes. No caso do Brasil, por exemplo, uma sociedade na qual valores hierárquicos são importantes no cotidiano, a produção da liminaridade carnavalesca abre um espaço dentro do qual as pessoas podem sair de um universo marcado pela gradação e pela hierarquia, para experimentar a individualização, por meio de um conjunto de escolhas pessoais, bem como pela competição. Nesse sentido, a liminaridade carnavalesca brasileira promoveria uma experiência com um "eu essencial" e não com um "nós essencial", como Turner gostava de acentuar, sem atinar que com isso estava idealizando relações, uma ausência mais do que sentida no universo liberal e individualista do qual era parte. Um processo semelhante, mas inverso, tinha lugar no Mardi Gras de Nova Orleans e em ritos de iniciação americanos, nos quais o que se apresentava como foco vivencial era a coletivização dos noviços, simultaneamente iniciados na renúncia de um ego individualisticamente marcado e, em seguida, na obediência aos seus superiores e mestres de iniciação, quando são forçados a viver o coletivo de modo hierárquico e relacional. As iniciações americanas seriam marcadas pela ênfase na dimensão relacional e coletiva da vida social, ao passo que as brasileiras fariam justo o oposto. A formulação é incipiente e talvez sofra de demasiada simetria, mas tem a virtude de mostrar como a comparação por contraste permite escapar de um funcionalismo ingênuo, no qual o sentido é atribuído a essências, e não ao contexto.

Foi essa visada tipológica, na qual a liminaridade era essencializada, que, a meu ver, barrou uma outra percepção fundamental por parte de Turner. Refiro-me ao discernimento das dimensões individualizantes (mas sem individualismo) contidas nos processos liminais. Ou, em outras palavras, nas semelhanças cruciais, vigentes nas sociedades tribais, entre liminaridade e individualidade, pois, o fato mais característico da transição dos noviços, de Van Gennep a Turner, é o fato de eles serem separados da sociedade e colocados fora do mundo. De um ponto de vista funcional, sua posição não seria muito diferente da dos renunciadores indianos de Dumont, dos profetas de Israel de Weber, dos feiticeiros e bruxos de Evans-Pritchard, do Antônio Conselheiro de Euclides da Cunha (cf. DaMatta, 1979b: caps. V e VI) e dos heróis civilizadores das mitologias tribais. 
Deixem-me, pois, terminar elaborando esse ponto, que permitirá juntar, de um lado, processos interpretados como estáticos e anti-históricos, máquinas de reter e deter o tempo, como diria Lévi-Strauss dos ritos de passagem, e, de outro, instituições historicamente dinâmicas - aceleradores do tempo como o nosso viés ocidental gosta de imaginá-las -, tais como a renúncia do mundo, as peregrinações, as profecias e os profetas que, em um processo dialético com a sociedade, movimentam suas estruturas, partejando visões de mundo paralelas e conflitantes, desafiadoras dos valores, e nela introduzem uma consciência diferenciada da moralidade e do tempo, essas dimensões que são o pano de fundo da consciência de mudança social.

Meu argumento central é o seguinte: o que caracteriza a fase liminar dos ritos de passagem é a experiência da individualidade vivida não como privacidade ou relaxamento de certas regras (pois o neófito está sempre sujeito a inúmeras regras), mas como um período intenso de isolamento e de autonomia do grupo. Mas, o que temos aqui é a experiência com a individualização como um estado, não como uma condição central da condição humana. Ou seja, a individualização dos noviços nos ritos de passagem não envereda pelo estabelecimento de uma ruptura, por meio da ênfase extremada e radical em um espaço interno ou em uma subjetividade paralela ou independente da coletividade; antes, pelo contrário, essa individualização é inteiramente complementar ao grupo. Trata-se de uma autonomia que não é definida como separação radical, mas como solidão, ausência, sofrimento e isolamento que, por isso mesmo, acaba promovendo um renovado encontro com a sociedade na forma de uma triunfante interdependência quando, na fase final e mais básica do processo ritual, os noviços retornam à aldeia para assumir novos papéis e responsabilidades sociais. Tudo se passa como se nos ritos de passagem, a reclusão, a individualização e a invisibilidade dos noviços fossem classificadas como estados negativos, como situações perigosas e anti-sociais que o estar fora-do-mundo (com sua pletora de mortificações) caracteriza, e que aproxima os neófitos dos feiticeiros, dos xamãs, dos heróis civilizadores, dos profetas e de outras figuras associadas a esse estado de distanciamento da sociedade.

No caso dos índios de língua jê, por exemplo, mitos envolvendo a aquisição de elementos civilizadores importantes como o fogo, a agricultura e a arte de curar, são obtidos por personagens que voluntária ou involuntariamente se isolaram, tiveram experiências críticas e, retornando 
ao grupo, integraram-se a ele como heróis em uma posição social diferenciada. O mesmo ocorre com os feiticeiros que geralmente aprendem sua magia fora do grupo, mas são socialmente descritos em toda parte como egoístas, desejosos de riqueza e motivados por agendas próprias. Seja entre os Navajos de Clyde Kluckholn, entre os Apinayé (por mim estudados) e nas mais diversas sociedades africanas, como revelam os casos reunidos por John Middleton e Edward Winter (1963), os feiticeiros são sempre caracterizados como pessoas bem-sucedidas economicamente, como não-conformistas, ou rebeldes, como cosmopolitas, que, voltando à aldeia, se marginalizam, ou como movidas pela acumulação de bens materiais, um claro sintoma de desdém pelas obrigações da reciprocidade. Feiticeiros são seres que preferem viver individualística e egoisticamente, recusando cumprir as obrigações devidas ao parentesco, ao clã e à aldeia. Realmente, a descrição da personalidade dos feiticeiros tribais corresponde, de perto, ao modelo de um indivíduo ou cidadão moderno, uma pessoa motivada pela riqueza, pela consciência de seu valor, pela independência de sua ação e, acima de tudo, centrada em si mesma, imersa na sua subjetividade ${ }^{7}$.

É curioso, sem dúvida, constatar que os pesquisadores ingleses e americanos do assunto tipifiquem a feitiçaria como um "crime" ou um "ill-feeling", reveladores de "sociedades com uma estrutura rígida" quando, de fato, estão lidando com uma manifestação da ideologia individualista em sistemas relacionais e holísticos. Isso é patente quando, por exemplo, Laura Bohanan (1966) acentua que "a tradução mais correta para 'estudioso' [ou sábio, scholar] (um homem que sabe das coisas) entre os Tiv, é feiticeiro". Confirma isso a observação pertinente de Evans-Pritchard, segundo a qual, entre os Azande, a feitiçaria é "geralmente considerada um traço individual apesar de suas ligações com o parentesco (cf. EvansPritchard 1965:25, ênfase minha), o que revela a associação dos feiticeiros com um individualismo que, aqui, surge não como um valor, mas como uma escolha negativa e marginal. Como uma força capaz de engendrar seres humanos invertidos e anticomplementares, que fazem tudo ao contrário, que desdenham dos seus parentes, comem seus companheiros de aldeia e abominam a regra de ouro da reciprocidade. Porém, diferente do caso dos renunciadores e dos profetas, essa experiência dos heróis míticos e dos feiticeiros das sociedades tribais não leva a uma diferenciação ou a uma renovação filosófica ou religiosa radical ou alternativa. Tal seria o caso, de acordo com Dumont (1985) e Weber (1971: cap. XIII), do renunciante indiano, dos anacoretas cristãos, dos andarilhos gregos do período pré-socrático, até os reformadores protestantes que põem Deus e 
religião em todas as esferas deste mundo ${ }^{8}$. Muito pelo contrário, esse estado fora-do-mundo (e, para usar expressão de Weber, de "rejeição do mundo"), típico dos ritos de passagem e da feitiçaria, conduz a uma complementaridade e a uma interdependência, inclusive corporal, que se manifestam explicitamente em vários grupos. Aqui, o que está em jogo não é construir um ser psicológica e existencialmente autônomo, mas moldar subjetividades cuja consciência não pode prescindir dos seus companheiros e mestres de iniciação, aqueles que o mortificaram e marcaram o seu corpo, deixando nele o testemunho de seu elo com o grupo na forma de um buraco, um corte e uma cicatriz. A rejeição do mundo, como acentuou Weber, legitima um certo "domínio do mundo em virtude dos poderes mágicos obtidos pela renúncia" (1971:375). O que se explicita nas iniciações não é o triunfo da autonomia, do espaço interno e do isolamento, mas a glória do elo e a exaltação do retorno à aldeia como alguém que renovou sua consciência de complementaridade e o seu débito para com a sua sociedade. Como os heróis míticos que retornam à aldeia com um novo item civilizador, roubado ou descoberto em uma experiência fora-do-mundo e em contato com animais ou espíritos, os iniciandos também retornam às suas comunidades com o aprendizado de que os elos igualitários com os companheiros de iniciação, a intensidade das emoções e mortificações desnudadas pela experiência de isolamento, são complementares à condição de pertencer a uma rede imperativa de parentesco que, em um sentido preciso, responde a todas as indagações intelectuais e tem como alvo curar a doença, manter o bem-estar e aliviar o sofrimento. Nos ritos de iniciação, os neófitos dramaticamente conjugam individualidade e coletividade, pois neles se reafirma que coletivo e individual constroem-se simultaneamente, sem fendas, descontinuidades ou separações. Se não fosse falar demais, dir-se-ia que ali eles entendem que o eu não existe sem o outro, e que no centro dos ritos de iniciação está a descoberta (ou melhor, o desvendamento) do mistério segundo o qual tanto a dimensão individual quanto a coletiva são construídas por um mesmo conjunto de valores.

Se há um denominador comum entre noviços, renunciantes, mágicos, profetas e feiticeiros, este não seria a privacidade ou a criação de uma subjetividade paralela e homogênea à sociedade, livre de peias sociais, mas seria, com certeza, a experiência individualizante que passa por uma visão relativizadora ou carnavalizada da sociedade, na qual o de dentro e o de fora, o parente e o afim, o forte e o fraco, o pobre e o nobre, o homem e a mulher, o jovem e o velho, os vivos e os mortos, confundemse e trocam de lugar, criando uma perspectiva em que as práticas e os 
valores cotidianos são invertidos, inibidos ou temporariamente substituídos, para logo se reencontrarem no alívio de uma complementaridade rotineira, mas agora renovada e triunfante. Desse modo, a família (hierarquizada por obrigações fundadas em substância comum) transformase em grupo de idade, cujo componente básico é a camaradagem e a simpatia; as obrigações de casta, segmento ou classe dão lugar a uma liberdade desconhecida e à capacidade de romper barreiras morais normalmente intransponíveis.

O resultado da experiência, entretanto, não é produzir, como sempre ocorre entre nós, modernos, escolhas entre perspectivas, mas de entender a sua polaridade essencial. É inegável, porém, que tanto para os iniciandos quanto para os renunciantes, profetas e feiticeiros, a vida extramundana relativiza muitos axiomas da vida social: os genitores e a sexualidade são dessacralizados, o prazer e o bem-estar pessoal são sacrificados em nome de um estoicismo fulgurante, o axioma da amizade é substituído por agendas individuais muito fortes como o uso de emblemas individuais, a escolha de companheiros de ordálio, comidas singulares e um comportamento distinto, freqüentemente caracterizado como motivado por uma ambição avassaladora. A reclusão engendra um nicho no qual todos os elos diários perdem a força, deixando vir à tona a vivência do isolamento e da solidão que, no caso das sociedades tribais, recebe um sinal sempre perigoso e negativo.

É, sem dúvida, esse contato com a individualidade que faz com que, em toda parte, os noviços sejam perigosos e, por isso mesmo, recebam como os espíritos, alguns animais e os feiticeiros - um tratamento especial. Assim sendo, quero sugerir que o traço distintivo da liminaridade é a segregação de uma pessoa (ou de uma categoria de pessoas, tratadas como corporação social ou mística) dos seus laços sociais imperativos, liberando-a temporariamente das suas obrigações de família, linhagem, clã ou aldeia, o que a transforma temporariamente em indivíduo fora-domundo. Em gente sem laços sociais que permitam sua classificação social cabal e definam, assim, suas obrigações para com a sociedade. É precisamente essa "desclassificação" constituída pela rejeição do mundo que possibilita a constituição de uma sociabilidade inusitada e distinta, criando novas experiências fundadas em uma "liberdade" que se nutre da experiência da individualização.

Tal como ocorre com os profetas e renunciadores, essa experiência de se situar temporariamente fora-do-mundo tem - e esta é uma das principais características dos ritos de passagem - um sem-número de traços negativos. Se, no caso dos renunciadores e profetas, porém, o peso 
da experiência pode ser sublimado e legitimado como "missão" ou "nova mensagem", criando outras perspectivas dentro de uma mesma tradição religiosa, nas sociedades tribais a intenção parece ser a de marcar o potencial criador, mas negativo e, no limite, destruidor da experiência de estar isolado. Por isso, em muitos sistemas relacionais, ficar só é estar disponível para dialogar com fantasmas e monstros. Isolar-se é obrigatório e legítimo somente para buscar o contato com seres poderosos e letais como acontece na vision quest dos índios das planícies, estudados por Robert Lowie (1954) —, ou passar por ordálios, sofrer dor física, ter as orelhas ou lábios furados, ser circuncidado, jejuar, ficar acordado, decorar textos etc., situações nas quais a sociedade penetra o corpo dos noviços, marcando e como que dissolvendo suas pessoas ${ }^{9}$, seus órgãos genitais, cabeça, cabelos, braços, lábios e orelhas. Esses lábios e orelhas que, como Anthony Seeger (1980) revelou, são — no caso das sociedades jê — os instrumentos da boa sociabilidade e repositório de valores coletivos.

Tudo isso revela uma boa distância da concepção moderna de subjetividade, pois o que os ritos de passagem acentuam vai na direção de uma subjetividade interdependente, ao passo que a nossa subjetividade é construída salientando uma interioridade marcante - aquela "interioridade" (inwardness) que é a fonte central do "eu" para Taylor. Entre nós, modernos, trata-se de uma subjetividade que, como Greta Garbo, pede para ficar só, entende que o inferno são os outros e, como mostra o caso de Robinson Crusoe, jamais deixa de calcular os recursos disponíveis, não se intimidando ou desesperando pela solidão extremada. Nestes casos, o isolamento e a solidão abrem e acentuam um intenso diálogo interior, típico do individualismo moderno. Um diálogo glorificador da autonomia, da privacidade, do autodesenvolvimento, sociocentricamente confundido, como ilustra Steven Lukes (1973), com a dignidade do homem, no qual a capacidade de permanecer indiviso é um sinal de integridade e de força de caráter ${ }^{10}$.

Pode-se ampliar o argumento para acentuar uma oposição bem marcada entre a individualidade, que vivencia e conceitualiza o coletivo como complementar, e o individualismo, que vivencia o afastamento do grupo como um movimento marcado por interioridade e subjetividade. Em um caso a solidão serve para pensar melhor a sociedade; no outro, ela é a única maneira de pensar. Como resultado, o primeiro caso conduz à interdependência; já o segundo, abre caminho para o englobamento da sociedade pelo indivíduo compartimentalizado que tem necessidade de "liberty" e "freedom". Liberdade que é o sentimento de não ser subjugado, de fazer como bem entende, mas transformada em valor, que no 
mundo moderno se transforma em "freedom": a motivação inalienável de ser determinado de dentro para fora que constitui o centro do conceito de "autonomia" e conduz a uma oposição dupla entre indivíduo e sociedade. Primeiro, no conflito trivial do indivíduo contra a sociedade quando ele (ou ela) luta por seus direitos ou pela libertação dos costumes. Segundo, quando o indivíduo, integrado por sua auto-suficiência (self-reliance), ousadia (boldness), ambição (ambitiousness) e espírito aventureiro (venturesomeness), produz bem-estar social por meio de sua capacidade empreendedora, ou entrepreneurship ${ }^{11}$.

Do interior dessa ideologia, faz sentido afirmar com veemência:

“Eu desejo que minha vida e decisões dependam de mim e não de alguma força externa de qualquer tipo. Eu desejo ser o instrumento de mim mesmo, e não dos atos de vontade de outros homens. Desejo ser o sujeito, não um objeto; ser movido por razões, por propósitos conscientes que são meus, e não por causas acidentais que possam me afetar de fora. Eu desejo ser alguém, não ninguém; [ser] um fazedor — decidindo e não sendo decidido; ser autodirigido e não ser moldado por uma natureza externa ou por outros homens como se eu fosse uma coisa, um animal ou um escravo incapaz de desempenhar um papel humano, isto é, de conceber objetivos e rumos próprios e realizá-los. Isto é o mínimo que significa quando eu digo que sou racional e que é a minha razão que me distingue como um ser humano do restante do mundo" (Berlin 1969).

Lida para qualquer membro das sociedades que alguns de nós estudamos, essa glorificação do isolamento e da autonomia individual poderia ser tomada como um "manifesto da feitiçaria" - ou como uma declaração de supremo egoísmo. No entanto, trata-se de uma passagem escrita por Isaiah Berlin em um de seus célebres ensaios sobre um dos atributos mais básicos do indivíduo como valor: a liberdade que, para ele, pode ser vista por meio de dois conceitos e perspectivas. Em um plano efetivamente relativizador e antropológico, entretanto, as idéias de Berlin podem ser lidas como um insuspeito sumário de uma atitude na qual os indivíduos nada devem à coletividade. Muito pelo contrário, devem englobála, pois são moralmente superiores a ela.

Já nas sociedade tribais, o ponto dos ordálios não seria criar equivalências ou abrir novos caminhos, mas usar o isolamento como método para estabelecer interdependências dos iniciandos com o grupo. No fundo, e ao reverso, o dado mais crítico dos rituais de iniciação (e talvez a razão pela qual eles sejam levados a efeito) tem a ver com essa experiên- 
cia radical, e ao mesmo tempo controlada, da individualidade e do afastamento da sociedade, pois por meio deles se engendra uma disciplina baseada em uma estranha dialética de independência e dependência quando se mostra aos neófitos as potencialidades do isolamento, da individualização e, ao mesmo tempo, incute-se neles uma lição profunda de complementaridade. Complementaridade esta que contrasta fortemente com a individualidade e que nós, brasileiros, conhecemos bem como dependência, lealdade, consideração e saudade. Esses valores que nos obrigam a passar por cima das leis para favorecer os amigos ${ }^{12}$.

Meu ponto central, então, é que a liminaridade dos ritos de passagem está ligada à ambigüidade gerada pelo isolamento e pela individualização dos noviços. É, portanto, a experiência de estar fora-do-mundo que engendra e marca os estados liminares, não o oposto. Em outras palavras, a liminaridade e as propriedades nela descobertas por Turner não têm poder em si mesmas. Mas é a sua aproximação de estados individuais que faz com que os noviços se tornem marginais. É, em uma palavra, a individualidade que engendra a liminaridade. No fundo, os ritos de passagem tratam de transformar individualidade em complementaridade, isolamento em interdependência, e autonomia em imersão na rede de relações que os ordálios, pelo contraste, estabelecem como um modelo de plenitude para a vida social.

Uma palavra final deve ser aduzida a esse exercício que muitos podem achar ingênuo, ou até mesmo despropositado. Afinal, sabemos todos, cada sociedade esconde dentro de si infinitos significados que sempre escapam desses exercícios gerais e ambiciosos de entendimento. Sou o primeiro a concordar com tal apreciação. Minha defesa, se defesa tenho, é a lembrança da anedota do estruturalista francês contada por Marshall Sahlins. Conta ele que, estudando estátuas eqüestres de vultos históricos, um estruturalista empedernido descobriu que quanto mais importante o vulto, mais patas do cavalo, como que a confirmar em um outro código a importância social do ator, estavam no ar. Finda a preleção, um pós-moderno questionou desdenhosamente: "mas, ninguém mais anda a cavalo..." . No que o estruturalista respondeu: "de fato, mas ainda erigimos estátuas". 
Roberto DaMatta ocupa a cátedra Rev. Edmund P. Joyce de Antropologia na University of Notre Dame, Indiana, Estados Unidos. É professor titular licenciado da Universidade Federal Fluminense. Escreveu, entre outros, Um Mundo Dividido: A Estrutura Social dos Índios Apinayé, Carnavais, Malandros e Heróis, A Casa e a Rua, O que Faz o Brasil, Brasil? e Conta de Mentiroso. Seu último livro, escrito com Elena Soárez, intitula-se Águias, Burros e Borboletas: Um Estudo Antropológico do Jogo do Bicho.

\section{Notas}

* "Conferência Castro Faria", proferida no Museu Nacional/UFRJ em 9 de agosto de 1999. No preparo para a publicação desta conferência, contei com sugestões valiosas do prof. Carlos Fausto. A profa Lívia Barbosa, do Departamento de Antropologia da Universidade Federal Fluminense, fez importantes comentários sobre as idéias centrais do trabalho. A ambos sou grato pelas opiniões que, naturalmente, não me eximem dos exageros e dos erros cometidos.

1 O chamado estudo mono-gráfico (etnografias são freqüentemente monografias escritas a partir da perspectiva de um único observador) de pequenas tribos, em geral relativamente isoladas. Estudos que, conforme sabemos, têm servido de caução contra as pretensões universais da visão Iluminista, pois seus achados formam o deleite antropológico quando permitem dizer: "isso pode ser 'verdade' no Ocidente, mas entre os 'Brasa-Bela' não é assim” (ver DaMatta 1987).

2 Max Weber nos fez ver como a ética protestante foi essencial para colocar a religião em todos os lugares e para ajudar a transformar o "indivíduo-fora-domundo" em uma entidade deste mundo. Vale consultar O Individualismo (1985) de Louis Dumont para uma visão elaborada dessa transição, à qual, inspirada em Weber, ele atribui a autonomização seriada dos domínios político e econômico do que chamamos de esfera da "religião" que, conforme já havia ensinado Durkheim, englobava tudo. Charles Taylor chega, sabendo ou não, por vias filosóficas e neoevolucionistas, próximo de Dumont quando diz que no self moderno, "pensamento e sentimento - o psicológico - estão agora confinados a mentes. Isto é coerente [continua ele] com o nosso desengajamento do mundo" (cf. Taylor 1989:186). 
3 Apreciei essa reação anglo-saxônica ou "ocidental" ao que seria uma avassaladora e deplorável coletivização nas observações marginais e introdutórias de Evans-Pritchard no seu livro sobre Os Nuer (1978), de Lévi-Strauss em Tristes Trópicos (1956), de Chagnon entre os Yanomamo (1968) e de Maybury-Lewis entre os Xavante (1967) (DaMatta 1981:169). Viveiros de Castro observa o mesmo ponto no trabalho de Thomas Gregor no Xingu, todo ele marcado por um individualismo implícito e inconsciente (ver Seeger, DaMatta e Viveiros de Castro 1979).

4 Essa perspectiva relativiza criticamente uma situação recorrente nos estudos brasileiros, ultrapassando as análises baseadas em tipos institucionais acabados e essencializados — "democracia", "feudalismo", "subdesenvolvimento", "mercado" etc. - bem como em um evolucionismo um tanto infantil, pronto a afirmar que o "Brasil é um país ainda na infância", daí as suas dificuldades com o quadro institucional burguês e moderno, constituído em países "mais velhos", "mais adiantados" e "mais maduros", ou "experientes".

5 O qual desenha no poema Bishop Blougram's Apology publicado no livro Man and Woman, em 1855, a ambigüidade como o elemento mais fascinante da condição humana, afirmando:

Nosso interesse está na margem perigosa das coisas.

O ladrão honesto,

O homicida compassivo,

$\mathrm{O}$ ateu supersticioso,

A mulher de reputação duvidosa, que ama e salva sua alma em novos livros franceses.

Nós ficamos observando, enquanto eles se mantêm em equilíbrio, Acompanhando a vertiginosa linha intermediária.

6 "Teoria da ambigüidade" que - hoje tenho consciência disso —, talvez, tenha sido o momento em que a antropologia mais se aproximou de uma teoria geral da sociedade, análoga à teoria geral dos preços e do mercado na economia e do ego e do inconsciente na psicologia.

7 Uma das formas de amor mais populares nos Estados Unidos é o "selflove" - o amor de e para si mesmo. Amor que é a semente da autoconfiança e da auto-estima, esses pilares da construção da subjetividade no chamado individualismo moderno.

8 Sobre os gregos, já Van Gennep (1978) acentuava que uma fase importante da iniciação dos jovens, quando eram levados à beira do mar, se denominava elasis, isto é, remoção ou banimento.

9 Duas monografias sobre a noção de "eu" e de "pessoa" na Índia ressaltam bem esse ponto, pois tanto entre os tamil, quanto na tradição do budismo teravada, temos, respectivamente, seres marcados por substâncias fluidas e, do ponto de vista ocidental e moderno, uma contradição em termos: "selfless persons" (pessoas sem eu) (cf. Daniel 1984 e Collins 1982). 
10 Tudo, como se observa, que tem a ver com traço exclusivo, com marca distintiva única e com integração sólida, sinal de que a entidade assim constituída tem fronteiras bem delimitadas. Ora, isso é o oposto da idéia de personalidade vigente nas sociedades tribais, onde o "eu" é sempre dividido em muitas partes e/ou almas. Veja-se a reação de Taylor perante o fato de os Buriats da Sibéria terem três almas (Taylor 1989:113). Veja-se também a admoestação "dumontiana" de Geertz, que aqui segue em uma tradução livre: "A concepção Ocidental de pessoa como um universo compartimentalizado, único e motivacionalmente mais ou menos integrado, um centro dinâmico de consciência, emoção, julgamento e ação, organizado em uma totalidade distinta e em um conjunto contrastivo em relação a outras totalidades semelhantes e contra o seu cenário social e natural é, ainda que isso possa ser um fato incorrigível para nós, uma idéia um tanto peculiar dentro do contexto das culturas do mundo" (cf. Geertz 1983:59).

11 Devo parte dessas observações a Lívia Barbosa que acentua, com sua perspicácia habitual, que o "entrepreneurship" não é um valor no Brasil. Pelo contrário, muitas dessas conotações positivas da idéia de liberdade e de "freedom" são tomadas como negativas em muitas sociedades. No Brasil são geralmente lidas como "egoísmo".

12 Não resisto à tentação de citar um trecho provocador do ensaísta mexicano Gabriel Zaid, que traduzo livremente: "Uma vez pensei em escrever uma tragicomédia sobre a corrupção no México, através de um personagem incorruptível que, por sua honestidade, provoca uma desgraça atrás da outra. Seu desejo de fazer o bem causa o mal: arruína sua família, estorva desastrosamente aqueles que queria ajudar, faz com que percam o emprego, hostiliza os vizinhos e dá origem a mortes, ódios, fome, ruína. Acaba renegado por seus filhos, abandonado por sua mulher, sem amigos e expulso de sua cidade. No México a honestidade é tragicômica" (Zaid 1989). 


\section{Referências bibliográficas}

BAKHTIN, Mikhail. 1989. A Cultura Popular na Idade Média e no Renascimento: O Contexto de François Rabelais. São Paulo: Hucitec.

BERLIN, Isaiah. 1969. Four Essays on Liberty. Oxford e New York: Oxford University Press.

BOHANAN, Laura. 1966. "Shakespeare in the Bush". Natural History, agosto/setembro.

CHAGNON, Napoleon. 1968. Yanomamo: The Fierce People. New York: Reinehart \& Winston.

COLlins, Steven. 1982. Selfless Persons: Imagery and Thought in Therevada Buddhism. Cambridge: Cambridge University Press.

DAMATTA, Roberto. 1979a. "Ritual in Complex and Tribal Societies". Current Anthropology, 20(3). .1979b. Carnavais, Malandros e Heróis: Para uma Sociologia do Dilema Brasileiro. Rio de Janeiro: Rocco. . 1981. Universo do Carnaval: Imagens e Reflexões. Rio de Janeiro: Edições Pinakhotteke. 1987 [1981]. Relativizando: Uma Introdução à Antropologia Social. Rio de Janeiro: Rocco.

DANIEL, E. Valentine. 1984. Fluid Signs: Being a Person the Tamil Way. Berkeley e Los Angeles: University of California Press.

DOUGLAS, Mary. 1966. Purity and Danger. London: Routledge \& Kegan Paul.

DUMONT, Louis. 1985 [1983]. O Individualismo. Rio de Janeiro: Rocco.

EVANS-PRITCHARD, E. E. 1965. Witchcraft, Oracles, and Magic: Among the Azande. Oxford: Clarendon Press. .1978. Os Nuer. São Paulo: Perspectiva.
GEERTZ, Clifford. 1983. Local Knowledge: Further Essays in Interpretative Anthropology. New York: Basic Books. LEACH, Edmund R. 1964. "Anthropological Aspects of Language: Animal Categories and Verbal Abuse". In: E. H. Lenneberg (ed.), New Directions of the Study of Language. Cambridge: The MIT Press. pp. 22-63.

LÉVI-STRAUSS, Claude. 1956. Tristes Trópicos. São Paulo: Anhembi.

LOWIE, Robert H. 1954. Indians of the Plains. New York: McGraw-Hill/ American Museum of Natural History.

LUKES, Steven. 1973. Individualism. New York: Harper Torchbooks.

MAUSS, Marcel. 1974 [1938]. "Uma Categoria do Espírito Humano: A Noção de Pessoa". Antropologia e Sociologia. São Paulo: Editora Pedagógica/Edusp. pp. 207-241.

MAYBURY-LEWIS, David. 1967. AkweShavante Society. Oxford: Clarendon Press.

MIDDLETON, John e WINTER, Edward. 1963. Witchcraft and Sorcery in East Africa. London: Routledge \& Kegan Paul.

SEEGER, Anthony. 1980. "O Significado dos Ornamentos Corporais". In: Os Índios e Nós: Estudos sobre Sociedades Tribais Brasileiras. Rio de Janeiro: Editora Campus. pp. 43-60. , DAMATTA, Roberto e VIVEIROS DE CASTRO, Eduardo. 1979. "A Construção da Pessoa nas Sociedades Indígenas Brasileiras". Boletim do $\mathrm{Mu}$ seu Nacional (nova série): 32:2-19.

TAYLOR, Charles. 1989. Sources of the Self: The Making of the Modern Identity. Cambridge: Harvard University Press. 
TURNER, Victor. 1964. "Betwixt and Between: The Liminal Period in Rites de Passage". The Proceedings of the American Ethnological Society. (Republicado em The Forest of Symbols: Aspects of Ndembu Ritual, New York, Cornell University Press). . 1974 [1969]. O Processo Ritual: Estrutura e Anti-Estrutura. Petrópolis, R.J.: Vozes.

VAN GENNEP, Arnold. 1960 [1909]. The Rites of Passage. Chicago: Phoenix Books/University of Chicago Press. (Tradução brasileira: Os Ritos de Passagem, Petrópolis, R.J. Vozes, 1978.)

VIVEIROS DE CASTRO, Eduardo. 1987. "A Fabricação do Corpo na Sociedade Xinguana". In: J. P. de Oliveira Filho (org.), Sociedades Indígenas e Indigenismo no Brasil. Rio de Janeiro: Marco Zero/Ed. UFRJ. pp. 31-41.

WEBER, Max. 1971. Ensaios de Sociologia. Rio de Janeiro: Zahar Editores. .1981. A Ética Protestante e o Espírito do Capitalismo. São Paulo: Editora Pioneira.

ZAID, Gabriel. 1989. "La Propriedad Privada de las Funciones Públicas". Vuelta, 120:25-32. 


\section{Resumo}

Este artigo explora um elo crítico entre dois conceitos centrais das ciências sociais: a idéia de liminaridade engendrada pela tradição antropológica dos estudos monográficos, autocontidos e auto-referidos, e a idéia de individualidade, noção central da tradição clássica dos estudos sociohistóricos das grandes civilizações (além de categoria crucial e familiar do nosso universo cívico e político). O autor procura indicar como uma passagem pode ser descoberta entre essas duas áreas conceituais aparentemente tão distantes, focalizando certos aspectos ainda não discutidos dos ritos de passagem. Argumenta-se que a liminaridade dos ritos de passagem está ligada à ambigüidade gerada pelo isolamento e pela individualização dos noviços, e que, portanto, a experiência de estar fora-do-mundo é que engendra e marca os estados liminares, e não o oposto - é a individualidade que engendra a liminaridade. Os ritos de passagem transformam essa experiência em complementaridade, em imersão na rede de relações que os ordálios, pelo contraste, estabelecem como um modelo de plenitude para a vida social.

\section{Abstract}

This article explores a critical link between two concepts which are central to the social sciences: the idea of liminarity, engendered by the anthropological tradition of self-centred and self-referred monographic studies; and the idea of individuality, a key concept within the classical tradition of the socio-historical studies of great civilizations (as well as being the crucial and familiar category of our civil and political universe). The author seeks to show how a bridge can be established between these two concepts, which may at first appear distant, by focusing on certain under-discussed aspects of rites of passage. It is argued that the "liminal" stage of rites of passage is tied to the ambiguity brought about through the isolation and individualization of the initiate. It is therefore the experience of being "outside-the-world" which brings about and characterises liminal states, and not the other way around in short, it is individuality which engenders liminarity. Rites of passage transform this experience into complimentarity, into an immersion into a network of social relationships, which the ordeals, in contrast, establish as a model for the plenitude of social life. 